\title{
Research on the College Library Information Literacy Education in MOOC Environment
}

\author{
Qi Ning* \\ Library \\ Shenyang Jianzhu University \\ Shenyang, China \\ e-mail: arnold0110@ sina.com \\ * Corresponding Author \\ Zhang Dongwei \\ Information \& Control Engineering Faculty \\ Shenyang Jianzhu University \\ Shenyang, China \\ Li Jiyong \\ Graduate department \\ Dalian university of foreign languages \\ Dalian, China \\ Mao Yongming \\ Information \& Control Engineering Faculty \\ Shenyang Jianzhu University \\ Shenyang, China
}

\author{
Wang Xin \\ School of Information \& Control Engineering \\ Shenyang Jianzhu University \\ Shenyang, China \\ Wang Changtao \\ School of Information \& Control Engineering \\ Shenyang Jianzhu University \\ Shenyang, China \\ Zhang Hui \\ School of Information \& Control Engineering \\ Shenyang Jianzhu University \\ Shenyang, China \\ Wang Bin \\ Northeastern University at Qinhuangdao \\ Qinhuangdao, China
}

\begin{abstract}
The emergence of massive open online courses, bring disruptive changes to higher education. This method is based on students as the center, providing students with personalized education and support, and it focus on improving the students' interest in learning. It can stimulate students' initiative and the characteristics of creative thinking. This way of teaching is the subversion and challenge to the traditional education teaching mode.Now MOOC is using for college library to break time, place , identity restriction, fairness and permanent provides opportunities for information literacy education. This paper expounds the characteristics of MOOC and the influence on higher education. It also analyze the MOOC of information literacy education in teaching contents, teaching methods and the transformation of the education mode. Finally we put forward the university library information literacy education strategy in the MOOC environment.
\end{abstract}

Keywords- MOOC; College; Information literacy education; Education reform; Library;

\section{INTRODUCTION}

College library is one of the mainly platforms for college students' in the information literacy education. After 30 years of teaching practice and exploration, college library has achieved some results in improving college students' information retrieval, analysis and use and management. But with the rapid development of network technology and information technology, college students' learning environment and the way has changed greatly, and information literacy education is experiencing change. In order to improve the students' information literacy skills and level, college library has been exploring the reform of the information literacy education and countermeasures.

The emergence of MOOC bring disruptive changes to higher education. It is based on the students as the center, so as to provide personalized education and support, and it also pay attention to improve the learning interest, arouse the initiative and the characteristics of innovative thinking, and it is the subversion of traditional education teaching mode and the challenge. As well as the college library in meet the demand of personalized learning, it can provide service without restricted by time, place, identity of the equity, permanent information literacy education provided opportunities for development ${ }^{[1]}$.

\section{THE FEATURES AND INFLUENCE OF MOOC}

MOOC is the abbreviations of Massive Open Online Course. MOOC is the massive open online courses, which is given priority to video and interactive network curriculum posted on the Internet to many students around the world. MOOC is a few small video, it is teaching content, through which can test and interact to promote students' learning, and it can promote teachers improved teaching based on the large data analysis.

\section{A. The characteristics of the MOOC}

1) Massive. Different from traditional classroom teaching mode, MOOC has no restrictions to the number of students. The number of tens of thousands or even hundreds of thousands, millions of scale can be easily run. 
2) Open. MOOC emphasizes the learning resources sharing. Sharing means that all the people who want to learn, as long as he can hug terminals and network will be able to enjoy high-quality education resources. Learning resources are no longer limited. Everyone is not affected by age, nationality, time, location and other conditions. All the people can have a fair chance to learn ${ }^{[2]}$.

3) Personalized. MOOC can meet students' multilevel, diversified and multi-dimensional learning needs. Personalized is mainly for learning, all the students can select courses according to the own situation , preferences, the learning place, time. So the choice of the process can be fully customized.

4) Real-time interaction. MOOC can realize the communication pattern of traditional classroom. Students can ask questions through the MOOC platform, at the same time teachers can real-time answer questions to the students and carry out special explanation, also they can collect students' problems in curriculum optimization ${ }^{[3]}$. Real-time interactive can stimulate students' learning initiative, so it can cultivate the students' self-study ability, and improve the students' learning efficiency.

\section{B. MOOC Impact On Higher Education}

With the development of network technology, the presence of MOOC has huge impact on the traditional higher education. MOOC created a new kind of knowledge dissemination and access, it can not only provide students with the high quality teaching resources, but also can provide complete learning experience. MOOC can break the university walls, and dismantle the organization boundary and identity. It can give everyone a chance to receive higher education. Higher education is the elite education in the past, now MOOC contributed to higher education give the opportunity to make it become a mass education and universal education, even to achieve lifelong education. MOOC promote the popularization of higher education reform to the fair, lifelong, the direction of rapid development, the varieties for the construction of national education and lifelong education system. Promoted the education reform and development of our country has played a positive role.

\section{THE CHANGE OF INFORMATION LITERACY EDUCATION IN MOOC ENVIRONMENT}

Information literacy education put forward as early as 1974. Its essence is the information people who need to demand, and has the ability of acquisition, evaluation and the use of information ${ }^{[4]}$. At present domestic mainly to complete the information literacy education of university library, the library lecture courses in literature retrieval and user use methods such as improving the information retrieval ability of students, at the same time promote the extensive use of library resources. College library in the process of promoting utilization of information resources can provide students with the discovery of new knowledge, acquire and sharing method. It can improve the students' learning interest and ability, but also become a facilitator of the reform of information literacy education and the beneficiaries.

\section{A. Make Teaching Content From Single To Multiple}

MOOC can provide various forms of teaching content, each course includes teaching video, film editing, case demonstration, summed up documents, unit test, community discussion. MOOC emphasizes the multidirectional interaction and communication between teachers and students, by using a large amount of information on the MOOC platform products, teachers and students can become the discoverer of knowledge and topic maker. The diversification of teaching content has been far beyond the category of traditional information literacy education in colleges. College library in the information literacy education guides the student to knowledge discovery, acquisition, management and utilization of information. As we known promoting library resources flow and knowledge flow is one of the objectives of information literacy education reform.

\section{B. Teaching Way From One-way TO Multidirectional}

MOOC is not used for traditional teaching methods, from one-way transmission form into a multidirectional communication form, the classroom interaction part in inclass test, discussion, peer evaluation and large data analysis. In the MOOC in-class quiz can feedback and test students' knowledge level. Discussion can be used for the student to the knowledge and discussion topics, also convenient students communicate with real-time questions. Students can also through the evaluation of peer assignments to interactive ideas inspire innovative thinking. Finally through the large data analysis to the students' learning situation feedback to the teacher. The multidirectional communication way of teaching innovation in the information literacy education means was widely used in the way of social media expand the student exchange and sharing. It is easier to stimulate students' learning enthusiasm and interest.

\section{The Education Mode From Popular Tendency Of Personalized}

Since the college library carry out the information quality education, it has been trying to grope for master students of information behavior. Its purpose is to provide reference for evaluating and improving the information literacy education. Because the student's understanding ability are individual differences in the accumulation of knowledge, so the MOOC provides personalized learning one of the main factors that attract students, it also provide opportunities for the change of the traditional education mode. MOOC platform using big data technology collect basic data in the process of the students in each course, through system analysis can help teachers improve teaching content and teaching links. Through data mining teachers recommend personalized learning resources. MOOC combine mass and personalized teaching, make the college library can be timely grasp the students' information demand, improve the teaching links and content, provide more professional and personalized knowledge resources. It can make information literacy education mode transition from popularity to the personalized teaching. 


\section{COLLEGE LIBRARY INFORMATION LITERACY EDUCATION STRATEGY IN MOOC ENVIRONMENT}

In April 2015, the ministry of education give the opinion on MOOC platform and its extensive application. It can promote the teaching mode , teaching management system, contents, methods and mechanism change. It can also bring to the development of higher education teaching reform, new opportunities and challenges. College library should be as soon as possible to meet the needs of students' personalized development and diversification of lifelong learning, actively participate in the development of online information literacy education curriculum construction and maintenance, so as to promote the application of high quality education resources and sharing.

\section{A. Create MOOC information literacy program}

At present, most of the college library have the information literacy education elective courses, but due to limited staff, it is not good covered the entire school all levels personnel information literacy requirement. So the college library should be through the MOOC course of scientific research team, teaching team and provide personalized information literacy support students, so as to promote the teachers and students to better analysis, information exchange, knowledge sharing.

\section{B. Improve the ability of teachers' information literacy}

MOOC application has changed the traditional way of teaching, it promote the teachers from the knowledge disseminator into guidance. Through thought collision knowledge exchange and even become common learners, improving the ability of teacher's information literacy is essential.

College library can promote teachers' comprehensive understanding of the concept and application of MOOC, participate in relevant MOOC course, system design MOOC course outline, teaching outline. In order to improve teaching video interesting and attractive, the expanding process of interactive communication channels was built. To improve personal professional knowledge, it can learn advanced teaching ideas and methods, so as to improve the teaching level, actively mobilize students' learning enthusiasm, and guide students to participate in mutual discussion, improved the teaching content, listening to your students through the system study, goals, personality, learning ability and improve the students' information literacy levels ${ }^{[5]}$.

\section{Provide MOOC Learning Shared Space}

In the MOOC environment, learning style has been from the traditional one-way to the development of online hybrid combination of ways. Such as video and audio way class online learning classroom, the teacher recommend books journals class curriculum resources such as offline study way, also it have movies, games and practical way of learning, curriculum resources and notes of the students and teachers share way. In these ways, the students' union needs certain learning sharing space such as the space in the resources advantage, college library advantage, technology advantage, personnel advantages. So it can provide students with learning sharing space, including online learning of virtual space, information sharing space, communication space, offline entities learning space. At the same time, it can provide relevant learning services, consulting services, technical services, resource services, realize the combination of online and offline learning Shared space ${ }^{[6]}$.

\section{Embedded Service Guide Resource Utilization}

With the application of the MOOK, college library should also carry out MOOC related subject resource service, using the established subject librarian, provide MOOC course subject literature consulting and professional information. To guide and support teacher MOOC design creation, so as to make full use of it. It can also be free of curriculum resources in existing MOOC platform into the library's digital resources, and it provide the course information, course evaluation, feedback and learning related to the guidance of the personalized service, guides the student to study teacher MOOC supplement classroom learning ${ }^{[7]}$

\section{CONCLUSION}

MOOC appeared has brought opportunities and challenges for the reform and development of higher education, but also bring colleges information literacy education reform and innovation opportunities and challenges. The college library is the information resources storage and service center, and it is a center of promotion and share of information resources. So we should study MOOC environment of its own role, according to the characteristics of the MOOC for information literacy education to provide professional support, innovation service mode for students of fairness and permanent learning resources protection.

\section{REFERENCES}

[1] Jiang Lili, Chen Youhua. "Research on Key Success Factors of Information Literacy MOOCs in Academic Universities," Library and Information Service,2015,15,62-67.

[1] Wang Xin, Huang Kuan, Gao Zhijun. The Primary Users' Signals Recognition Algorithm in Cognitive Radio Networks via KPCA and Random Forest[J].ICIC Express Letters,2015, 9(4):1083-1088.

[2] He Lifang. "A Research into the Subject Service of Libraries against the Backdrop of MOOC," Library Journal,2015,03,53-59.

[3] YE Xiao-jiao, HE Jun-ying, and LIU Bo-ying. "Research on MOOC Combined with Classroom Teaching Mode in Information Literacy Education in Colleges," Journal of Xichang College. Natural Science Edition,2015,02,104-107.

[4] LIAO Min-xiu, LIU Jin-jun, and FAN Ya-fei. "New Exploration of Literature Retrieval Course Teaching under the Background of MOOC," Library Research,2015,04,103-106.

[5] Lu Chunhua. "Research on University Library Information Service for MOOC," Information Research,2015.,01,104-106.

[6] Lu Mei. "Strategies of American Library Responding to the MOOC and the Influence on the Chinese Academic Library," Library,2015,03,49-52.

[7] HE Jian-Ying, YAN Hai-Hua and JIN Mao-Zhong. Research of Vertical Search Engine Incorporating with Ontology Filtering and Text Mining. Computers Science,2008,02,188-190.

[8] LV Lin-tao, CHEN Li-ping and ZHOU Hong-fang. Topic Distillation Algorithm for Vertical Search Engine. Computer Engineering,2009,15,44-46.

[9] WANG Congrui and ZHANG Cui-xiao. A Vertical Search Engine System Model Based on Ontology. Journal of the Hebei Academy of Science, 2013,02,49-53.

[10] Wang Xin,Guo Lili,Ma Lina. Cooperative Spectrum Sensing Algorithm Based on Second User Selection and Random Forest Classification[J].ICIC Express Letters, Part B: Applications,2015, 6(3):845-850. 